\title{
Disjunction Errors in Qualitative Likelihood Judgment
}

\author{
Bruce W. Carlson \\ Ohio University \\ AND \\ J. Frank Yates \\ University of Michigan
}

\begin{abstract}
Probability thcory requircs that the disjunction of two events be judged at least as likely as either of those events. Two studies are described which imply that violations of this requirement are very common. The data also show that subjects do not commit disjunction errors because they misinterpret the disjunctive statement "A or B" to mean "A or B, but not both." Instead, the pattern of errors is consistent with a judgment process describable as averaging. These results provide support for a "signed combination model of qualitative likelihood judgment." This model generalizes a previous one which applied to judgments concerning conjunctive events (J. F. Yates and B. W. Carlson, 1986, Organizational Behavior and Human Decision Processes, 37, 230-253). (c) 1989 Academic Press, Inc.
\end{abstract}

A distinction is often drawn between the accuracy and coherence of probability judgments (e.g., Winkler \& Murphy, 1968; Yates, 1982). Probability judgments are accurate if they correspond to what takes place in the real world; they are coherent if they are internally consistent, that is, if they satisfy certain widely accepted principles about how probability judgments should relate to one another, such as the Kolmogoroff axioms (Hacking, 1965). Probability theory does not require that probability judgments be accurate. It does, however, demand that they be coherent.

One fundamental requirement of probability theory is the extension rule:

$$
\text { If } \mathrm{A} \supseteq \mathrm{B} \text {, then } P(\mathrm{~A}) \geqslant P(\mathrm{~B}) \text {. }
$$

That is, an event cannot be more likely than an event which contains it. The conjunction of two events is contained within each of those events.

This research was supported in part by National Science Foundation Grant BNS 8605422. Requests for reprints should be sent to Bruce W. Carlson, Department of Psychology, Ohio University, Athens, OH 45701. 
Thus, by the extension rule, a conjunction cannot be more likely than either of its constituent marginal events. Formally,

$$
P(\mathrm{~A} \& \mathrm{~B}) \leqslant P(\mathrm{~A}) \quad \text { and } \quad P(\mathrm{~A} \& \mathrm{~B}) \leqslant P(\mathrm{~B}) .
$$

Nevertheless, Tversky and Kahneman $(1982,1983)$ reported that people reliably judge a conjunction to be more likely than one of its two constituent events. Later, Yates and Carlson (1986) demonstrated that the incidence of such "conjunction errors" depends upon the perceived likelihoods of the marginal events composing the conjunction. For instance, when both marginals were thought to be likely it was not uncommon for the conjunction to be judged more likely than both of the marginals. Such conjunction errors occurred rarely otherwise.

The extension rule pertains to disjunctions just as it does to conjunctions. However, unlike a conjunction, the disjunction of two events contains both of those events. Thus, a disjunction must be at least as likely as either of its constituent marginal events. Formally,

$$
P(\mathrm{~A} \text { or } \mathrm{B}) \geqslant P(\mathrm{~A}) \quad \text { and } \quad P(\mathrm{~A} \text { or } \mathrm{B}) \geqslant P(\mathrm{~B}) .
$$

Do likelihood judgments for disjunctions conform to the extension rule? The existing evidence is mixed. Whereas Wyer (1976) and Morier and Borgida (1984) reported substantial violations of the extension rule for disjunctions, Beach and Peterson (1966), Wells (1985), and Biela (1986) found few such violations. Moreover, Biela concluded that, when his subjects did fail to follow the disjunction rule, often it was because they assigned the same probability to the disjunction as they did to the more likely of the marginal events. The lack of consensus among previous investigations implies that there is a need for careful study of how often and under what circumstances human likelihood judgments for disjunctions disagree with the extension rule. The present research was intended as an initial step in that direction.

Some likelihood judgments are "quantitative." That is, the person indicates a degree of certainty that an event will occur. An example is a meteorologist's statement that there is a $40 \%$ chance of snow tomorrow, i.e., $P^{\prime}$ (Snow) $=.40$, where $P^{\prime}$ indicates a probability judgment rather than a formal probability. Other likelihood judgments are "qualitative" (cf. Krantz, Luce, Suppes, \& Tversky, 1971, Chap. 5). That is, the person reports the relative likelihood of two or more events, e.g., that snow is more likely than rain. "Logically," the ordering of quantitative likelihood judgments should agree with an individual's explicit qualitative likelihood judgments. For instance, if a forecaster judges snow to be more likely than rain, we would expect the forecaster's probability judgment of snow to be greater than that of rain. However, there is no necessary relation 
between qualitative and quantitative likelihood judgments. In qualitative judgments, usually the alternatives can be compared directly. Attention is focused on aspects of the alternatives which distinguish them, and editing procedures can be adopted to reduce the difficulty in making the judgment (Kahneman \& Tversky, 1979; Russo \& Dosher, 1983; Tversky, 1969). In contrast, in quantitative judgments, usually each alternative must be judged individually. The simplifying strategies used to make qualitative judgments are not useful in making quantitative judgments. The preference reversal phenomenon exemplifies the differences between qualitative and quantitative judgment (Lichtenstein \& Slovic, 1971).

Some of the earlier studies of disjunction errors used quantitative judgments, while others required qualitative assessments. The present studies were intended to document the existence of disjunction errors using qualitative likelihood judgments and, if such errors are observed, to use the pattern of errors to shed light on the fundamental judgment processes people use.

\section{STUDY 1}

The first study sought initial indications of the extent of violations of the extension rule for disjunctions in qualitative likelihood judgment. As indicated above, our previous studies showed that the incidence of conjunction errors depends on the perceived likelihood of the relevant marginal events (Yates \& Carlson, 1986). There were no theoretical reasons to expect a comparable strong dependency for disjunction errors a priori. Nevertheless, the perceived likelihoods of the marginal events represent boundary conditions that should not be dismissed in advance. Thus, an attempt was made to vary the likelihood of the marginal events.

\section{Method}

Subjects. One hundred five subjects recruited from the clients at a local law office and from the students and staff at the University of Michigan participated in this experiment. The subjects were paid.

Materials. Subjects were presented a questionnaire containing four judgment problems. Each problem consisted of four events which the subjects were asked to rank order by their probability of occurrence, using the number 1 for the most likely event, the number 2 for the second most likely event, and so on. Only two of the problems were pertinent to the present study. ${ }^{1}$ These problems consisted of the four events: A, B, (A $\& B)$, and $(A$ or $B)$.

\footnotetext{
1 The other two problems were conjunction problems. These were discussed in Yates and Carlson (1986).
} 
Two versions of each problem were constructed. In one version (LL), both marginal events were expected to be seen as likely, i.e., more likely to occur than not; in the other version (UU), both marginal events were expected to be seen as unlikely, i.e., less likely to occur than not. Table 1 contains both versions of all four marginal events.

Two forms of the questionnaire were constructed. The two versions of each problem (LL vs UU) were randomly assigned to the two forms of the questionnaire subject to the restriction that the two forms contain two $\mathrm{LL}$ problems, including one disjunction problem, and two UU problems, including one disjunction problem.

Subjects completed the questionnaire individually.

\section{Results and Discussion}

The data from four subjects were excluded from the data analysis because the subjects assigned the same rank to two or more events. For the remaining subjects, the number of disjunction errors was recorded for each problem: 0 if a subject judged the disjunction to be more likely than both of the marginal events, 1 if a subject judged the disjunction to be less likely than one of the marginal events, and 2 if a subject judged the disjunction to be less likely than both of the marginal events. The data of the law office clients and the students were combined because no differences between the groups were detected.

The results are contained in Table 2 . They reveal that qualitative judg-

TABLE 1

Marginal Events for DisuUnction Problems in Study 1

\begin{tabular}{|c|c|c|c|}
\hline Problem & & Likely & Unlikely \\
\hline \multirow[t]{2}{*}{1} & A & $\begin{array}{l}\text { U.S. auto companies } \\
\text { will raise their average } \\
\text { car prices by at least } \\
\$ 25 \text {. }\end{array}$ & $\begin{array}{l}\text { U.S. auto companies } \\
\text { will raise their average } \\
\text { car prices by less than } \\
\$ 25 \text {. }\end{array}$ \\
\hline & B & $\begin{array}{l}\text { The Detroit Tigers will } \\
\text { end the season with a } \\
\text { better record than the } \\
\text { Cleveland Indians. }\end{array}$ & $\begin{array}{l}\text { The Detroit Tigers will } \\
\text { end the season with } \\
\text { no better record than } \\
\text { the Cleveland Indians. }\end{array}$ \\
\hline \multirow[t]{2}{*}{2} & $\mathrm{~A}$ & $\begin{array}{l}\text { Ronald Reagan will } \\
\text { carry the South in the } \\
\text { November } \\
\text { Presidential election. }\end{array}$ & $\begin{array}{l}\text { Walter Mondale will } \\
\text { carry the South in the } \\
\text { November } \\
\text { Presidential election. }\end{array}$ \\
\hline & B & $\begin{array}{l}\text { The movie "Breakin" } \\
\text { will not be nominated } \\
\text { for an Academy } \\
\text { Award as "Best } \\
\text { Picture." }\end{array}$ & $\begin{array}{l}\text { The movie "Breakin" } \\
\text { will be nominated for } \\
\text { an Academy Award as } \\
\text { "Best Picture." }\end{array}$ \\
\hline
\end{tabular}


TABLE 2

Percentage of Disjunction Errors by Marginal Event Likelihood in Study 1

\begin{tabular}{|c|c|c|c|c|c|c|}
\hline \multirow{3}{*}{$\begin{array}{c}\text { Marginal } \\
\text { events }\end{array}$} & \multicolumn{6}{|c|}{ Problem $^{a}$} \\
\hline & \multicolumn{3}{|c|}{ Cars/Tigers $^{b}$} & \multicolumn{3}{|c|}{ Election/"Breakin"c } \\
\hline & 0 & 1 & 2 & 0 & 1 & 2 \\
\hline $\mathrm{LL}$ & 30.0 & 32.0 & 38.0 & 27.5 & 29.4 & 43.1 \\
\hline UU & 45.1 & 45.1 & 9.8 & 36.0 & 40.0 & 24.0 \\
\hline
\end{tabular}

ments of disjunctions violate the extension rule. Indeed, for each problem over $50 \%$ of the subjects made at least one disjunction error.

No clear result emerged from the manipulation of the likelihoods of the marginal events. The incidence of disjunction errors depended upon the likelihood of the marginal events in Problem 1, but not in Problem 2. In Problem 1, double disjunction errors occurred more frequently in the likely-likely than in the unlikely-unlikely version.

\section{STUDY 2}

One clear finding emerged from the first study: Generally, likelihood judgments about disjunctions do not satisfy the extension rule. Study 2 had three aims: The first was to examine further the generality of extension rule violations. The second was to test a specific explanation for the violations based on how people interpret disjunctions. Assuming that this explanation might be ruled out, the third was to test a particular model for how qualitative judgments about disjunctions are generated. These aims are discussed in turn.

\section{Generality}

The generality issue was addressed along several fronts. First, three additional judgment problems with very different content from those used in Study 1 were employed. Next, recall that, in Study 1, subjects rankordered events A, B, (A \& B), and (A or B). That is, the irrelevant "filler" event was the conjunction ( $A \& B$ ). From the subject's point of view the conjunction might have taken primary attention, implying less careful consideration of the disjunction ( $\mathrm{A}$ or $\mathrm{B}$ ). This is possible because conjunctions were clearly of interest in all the other problems the subjects were asked to solve. Thus, in Study 2 the filler event was always a disjunction, too. Finally, generality was also examined as it applied to the likelihoods of the marginal events. In each problem in Study 1, it was 
intended that both of the marginals be seen as likely or that both be perceived as unlikely. In Study 2, there was an additional version of each problem in which one marginal event was to be likely, the other unlikely.

\section{Disjunction Interpretation}

Makus and Zajonc (1985) proposed that conjunction errors occur because subjects misinterpret the marginal event $A$ as the conjunction ( $A$ \& not B) due to the presence of the conjunction (A \& B). For example, after being asked to consider $(\mathrm{A} \& \mathrm{~B})=$ "Bill is an accountant who plays jazz for a hobby," $\mathrm{A}=$ "Bill is an accountant" would be interpreted as (A \& not B) = "Bill is an accountant who does not play jazz for a hobby." Morier and Borgida (1984) found evidence that this explanation may indeed account for some conjunction errors.

In Study 2 a similar explanation for disjunction errors was tested. In natural language, the word "or" is often used exclusively, to rule out the possibility that two alternatives will both occur. For example, a child may be allowed to have one kind of dessert or another, but not both. In probability theory, "or" is used inclusively, to indicate not only that one of two alternatives may occur, but that both may occur, also. Therefore, the hypothesis was tested that subjects make disjunction errors because they misinterpret the disjunction (A or B) as the event (A or B, but not both). Note that the extension rule does not require that any particular relationship hold between the events $A$ and $B$ and the event (A or B, but not both). The strategy for testing the misinterpretation hypothesis was to sometimes state the disjunction (A or B) explicitly in the form (A or B, or both). If the hypothesis were viable, the explicit format should have led to fewer disjunction errors.

\section{Signed Averaging Model}

Our previous studies (Yates \& Carlson, 1986) have shown that the following formalistic model provides a good account for some people's likelihood judgments for conjunctions.

A qualitative likelihood function $\lambda$ assigns to every event $A$ a real number $\lambda(A)$, its qualitative likelihood index. For events $A$ and $B, \lambda(A) \geqslant$ $\lambda(B)$ if and only if $A \geqslant_{L} B$, where $\geqslant_{L}$ is the qualitative likelihood judgment relation interpreted to mean "is at least as likely as."

For arbitrary event $A, \lambda(A)>0$ if and only if $A$ is seen as "likely," i.e., $A>{ }_{L} A^{\prime}$, where $A^{\prime}$ indicates the complement of $A ; \lambda(A)<0$ if and only if $A$ is seen as "unlikely," i.e., $A^{\prime}>_{L} A$; and $\lambda(A)=0$ if and only if $A$ is seen as "indifferent," i.e., $A={ }_{L} A^{\prime}$, where $=_{L}$ is the qualitative likelihood judgment relation interpreted to mean "is as equally likely as."

Qualitative likelihood indexes for conjunctions are derived from those 
for the constituent marginal events according to the following signed sum rule for conjunctions. For arbitrary events $\mathrm{A}$ and $\mathrm{B}$,

$$
\lambda(A \& B)=\lambda(A)+\lambda(B) .
$$

As can be readily seen, this model predicts that no conjunction errors will be made when both of the marginal events are seen as unlikely. It predicts single conjunction errors when one marginal event is unlikely, the other likely. It prescribes double conjunction errors when both marginals are thought to be likely.

To account for disjunction errors, the following signed averaging rule for disjunctions is proposed. Again, for any events A and B,

$$
\lambda(\mathbf{A} \text { or } \mathbf{B})=w_{1} \lambda(\mathbf{A})+w_{2} \lambda(\mathbf{B}),
$$

where $0 \leqslant w_{1} \leqslant 1,0 \leqslant w_{2} \leqslant 1$, and $w_{1}+w_{2}=1$. The signed averaging rule predicts that a single disjunction error will occur, as long as two marginal events are not seen as equally likely. In the latter case, events $A$, $B$, and (A or B) should all be considered equally likely to one another.

The structure described above is called the signed combination model of qualitative likelihood judgment. The aim of the model is to describe how a person uses some judgments to arrive at others. It remains to be shown why people follow the prescribed rules. However, it seems plausible that the summation aspect of the conjunction rule might derive its force from the linguistic connotations of the word "and," viz., that one event amplifies or enhances the effects of one with which it is conjoined. Similarly, the averaging feature of the disjunction rule might be compelling because the word "or" connotes compromise. Signing is superfluous for the averaging rule; the same predictions would follow regardless of the signs of the individual likelihood indexes. One reason signing is retained throughout the model is that subjects do in fact seem to classify events phenomenologically into the categories we have labeled "likely," "unlikely," and "indifferent" (Yates \& Carlson, 1986). A less important reason is that the resulting characterization is more parsimonious.

The third major aim of Study 2 was to test the averaging rule. In a given judgment problem, that rule predicts that single disjunction errors should predominate, unless the relevant marginal events are equally likely. In the latter case, since in the present procedures ordering was forced, random ordering of events A, B, and ( $A$ or B) should be observed. If A is likely and $B$ is unlikely, or vice versa, the prediction of the rule is clearly that (A or B) should be intermediate in judged likelihood. But suppose $A$ and $B$ are both seen as likely or are both thought to be unlikely. Then there is a greater chance that those events are perceived to be equally likely. Thus, the expectation that (A or B) would have intermediate likelihood 
should be weaker. Single disjunction errors did not predominate in Study 1. This might have been because a conjunction was used as the filler item, as explained earlier, or because the subjects did not classify the events as likely and unlikely the way we intended them to do so. Thus, to provide a cleaner test of the averaging rule, in Study 2, a disjunction was used as the filler item and the subjects themselves indicated explicitly how they classified the given marginal events.

\section{Method}

Subjects. One hundred seventy-four students at Ohio University participated in this study as a course-credit option for an introductory psychology class. They were not paid.

Materials and procedure. Each subject considered three problems presented in a questionnaire. Each problem consisted of four events: A, B, (A or B), and (not A or not B). The order of the problems and the order of the events within each problem were randomly determined. Table 3 contains the marginal events for the three problems. For each problem, subjects were asked to rank order the four events by their probability of occurrence, using the number 1 for the most likely event, the number 2 for the second most likely event, and so on.

Three versions of each problem were constructed. As in Study 1, there wcre likely-likely (LL) and unlikely-unlikely (UU) versions, for which it was expected that subjects would consider both marginal events to be likely or unlikely, respectively. There was also a likely-unlikely (LU) version, for which one marginal was to be seen as likely, the other unlikely. The three versions of a problem were assigned to three different questionnaires. Each questionnaire contained one LL, one LU, and one UU problem. A fourth questionnaire was constructed, identical to one of the first three, except that the disjunction (A or B) was replaced by the event (A or B, or both). Each subject received one of the four questionnaires.

After completing the three problems contained in the main questionnaire, the subject classified each marginal event in those problems as likely or unlikely, from his or her perspective. Specifically, the subject was asked to indicate whether each event or its complement was the one more likely to occur.

Each subject participated in one of two large group sessions.

\section{Results}

For each problem, the number of disjunction errors, 0,1 , or 2 , was recorded for each subject. It was also noted how the subject classified each marginal event as likely or unlikely. 
TABLE 3

Marginal Events for Disunnction Problems in Study 2

\begin{tabular}{|c|c|c|c|}
\hline Problem & Event & Likely & Unlikely \\
\hline \multirow[t]{2}{*}{1} & A & $\begin{array}{l}\text { Bo Derek will win an } \\
\text { Oscar for her next film. }\end{array}$ & $\begin{array}{l}\text { Bo Derek will not win an } \\
\text { Oscar for her next film. }\end{array}$ \\
\hline & B & $\begin{array}{l}\text { The Soviet Union will } \\
\text { keep its troops in } \\
\text { Afghanistan throughout } \\
\text { the remainder of this } \\
\text { year. }\end{array}$ & $\begin{array}{l}\text { The Soviet Union will not } \\
\text { keep its troops in } \\
\text { Afghanistan throughout } \\
\text { the remainder of this } \\
\text { year. }\end{array}$ \\
\hline \multirow[t]{2}{*}{2} & $\mathbf{A}$ & $\begin{array}{l}\text { Syria and Israel will not } \\
\text { sign a peace treaty by } \\
\text { the end of this year. }\end{array}$ & $\begin{array}{l}\text { Syria and Israel will sign a } \\
\text { peace treaty by the end } \\
\text { of this year. }\end{array}$ \\
\hline & B & $\begin{array}{l}\text { The Bill Cosby show will } \\
\text { be one of the top } 10 \\
\text { rated television shows } \\
\text { at the completion of the } \\
1985-86 \text { television } \\
\text { season. }\end{array}$ & $\begin{array}{l}\text { The Bill Cosby show will } \\
\text { not be one of the top } 10 \\
\text { rated television shows } \\
\text { at the completion of the } \\
1985-86 \text { television } \\
\text { season. }\end{array}$ \\
\hline \multirow[t]{2}{*}{3} & A & $\begin{array}{l}\text { It will be cooler in Athens } \\
\text { on November } 1 \text { than on } \\
\text { January } 1 \text { this year. }\end{array}$ & $\begin{array}{l}\text { It will be warmer in } \\
\text { Athens on November } 1 \\
\text { than on January } 1 \text { this } \\
\text { year. }\end{array}$ \\
\hline & B & $\begin{array}{l}\text { When the } 1986 \text { baseball } \\
\text { season ends, Pete Rose } \\
\text { will still be the manager } \\
\text { of the Cincinnati Reds } \\
\text { baseball team. }\end{array}$ & $\begin{array}{l}\text { When the } 1986 \text { baseball } \\
\text { season ends, Pete Rose } \\
\text { will no longer be the } \\
\text { manager of the } \\
\text { Cincinnati Reds } \\
\text { baseball team. }\end{array}$ \\
\hline
\end{tabular}

Disjunction errors occurred over $80 \%$ of the time in this experiment. This incidence of disjunction errors is even higher than that observed in Study 1 . It is comparable to the rate of conjunction errors reported in previous studies (e.g., Tversky \& Kahneman, 1982, 1983).

A loglinear analysis (Feinberg, 1977) was performed to evaluate the misunderstanding hypothesis. Subjects were classified by the number of disjunction errors they made, by the likelihood of the marginal events composing a disjunction, and by the wording of the disjunction, either ( $\mathrm{A}$ or B) or (A or B, or both). A model which excluded all terms that included the wording of the disjunction fit the data well $\left(\chi^{2}(6)=7.66, p=.264\right)$. Thus, there was no evidence that disjunction errors occurred because subjects misinterpreted the disjunction (A or B) as the event (A or B, but not both). The data were collapsed over the wording of the disjunction for the remaining analyses.

Separate analyses were conducted for each of the three problems. The 
TABLE 4

Percentage of Disjunction Errors by Marginal Event Likelihood in Study 2

\begin{tabular}{|c|c|c|c|c|c|c|c|c|c|c|c|c|}
\hline \multirow{3}{*}{$\begin{array}{c}\text { Marginal } \\
\text { events }\end{array}$} & \multicolumn{12}{|c|}{ Problem $^{a}$} \\
\hline & \multicolumn{4}{|c|}{ Derek/USSR ${ }^{b}$} & \multicolumn{4}{|c|}{ Syria/Cosby ${ }^{c}$} & \multicolumn{4}{|c|}{ Athens/Rose ${ }^{d}$} \\
\hline & $n$ & 0 & 1 & 2 & $n$ & 0 & 1 & 2 & $n$ & 0 & 1 & 2 \\
\hline LL & 73 & 26.0 & 42.5 & 31.5 & 53 & 15.1 & 58.5 & 26.4 & 37 & 21.6 & 37.8 & 40.5 \\
\hline I.U & 65 & 13.8 & 52.3 & 33.8 & 83 & 10.8 & 78.3 & 10.8 & 53 & 18.9 & 66.0 & 15.1 \\
\hline UU & 36 & 11.1 & 52.8 & 36.1 & 38 & 13.2 & 52.6 & 34.2 & 84 & 20.2 & 50.0 & 29.8 \\
\hline
\end{tabular}

results are contained in Table 4 . For eight of the nine possible comparisons, single disjunction errors predominated $(p<.001)$, as predicted by the signed averaging model.

There was no reliable indication that the incidence of disjunction errors depended upon the judged likelihood of the marginal events in Problems 1 and 3 (Problem 1: $\chi^{2}(4)=5.12, p=.275$; Problem 3: $\chi^{2}(4)=8.95, p=$ .062). However, there was evidence of such a dependency in Problem 2 $\left(\chi^{2}(4)=11.90, p=.018\right)$. A closer examination of the second problem revealed that single disjunction errors were relatively less likely to occur when both marginal events were judged to be either likely or unlikely than when one of the marginal events was judged to be likely and one unlikely. This same pattern was also present in Problem 3, although, as reported, the implied effect was not statistically significant.

\section{Discussion}

Disjunction errors were observed frequently in both studies reported here. As the final study demonstrated, these errors cannot be attributed to subjects having different interpretations of the relevant events than were intended by the investigators. The pattern of disjunction errors was the same whether the disjunction was worded (A or B) or (A or B or both). Thus, these judgment patterns result from underlying processes that follow rules fundamentally different from probability theory principles. The proposed signed combination model of qualitative likelihood judgment is one candidate for what those rules are.

As was the case for conjunction errors (Yates \& Carlson, 1986), disjunction errors have been obtained both for events which share a common generating process (Morier \& Borgida, 1984) and, in this study, for events 
which have distinct generating processes. This is what would be expected according to the signed averaging model.

The present results do not mean that people misunderstand the concepts implicit in probability theory. As Nisbett, Krantz, Jepson, and Kunda (1983) demonstrated, people are quite capable of reasoning statistically in certain situations. Nor does it mean that people find the principles of probability theory unacceptable. Indeed, we suspect that, if directly confronted with the disagreement between their judgments and the extension rule, virtually all our subjects would say that their judgments must have been in error (cf. Tversky \& Kahneman, 1983).

The most defensible position is that people employ a variety of different judgment procedures. Among those procedures are applications of the extension concept, as in probability theory, heuristics such as representativeness, causal reasoning schemas, formalistic routines, including the present signed combination rules, and undoubtedly others. As directly observed by Yates and Carlson (1986), within a short period of time a single individual can easily take several distinct approaches to problems that are formally equivalent to one another. And there must surely be individual differences in people's tendencies to rely upon some judgment mechanisms rather than others. Thus, it is not surprising that the signed combination model (nor any other known model) cannot fully account for all the data in the existing studies. But it seems to safe to conclude that at least some of the subjects' judgments arose from processes described by the signed combination model.

\section{REFERENCES}

Beach, L. R., \& Peterson, C. R. (1966). Subjective probabilities for unions of events. Psychonomic Science, 5, 307-308.

Biela, A. (1986). Psychological patterns in predicting disjunction and conjunction of clinical symptoms. Acta Psychologica, 61, 183-195.

Feinberg, S. E. (1977). The analysis of cross-classified categorical data. Cambridge, MA: The MIT Press.

Hacking, I. (1965). Logic of statistical inference. Cambridge: Cambridge Univ. Press.

Kahneman, D., Slovic, P., \& Tversky, A. (1982). Judgment under uncertainty: Heuristics and biases. Cambridge: Cambridge Univ. Press.

Kahneman, D., \& Tversky, A. (1979). Prospect theory: An analysis of decision under risk. Econometrica, 47, 263-291.

Krantz, D. H., Luce, R. D., Suppes, P., \& Tversky, A. (1971). Foundations of measurement. New York: Academic Press.

Lichtenstein, S., \& Slovic, P. (1971). Reversals of perference between bids and choices in gambling decisions. Journal of Experimental Psychology, 89, 46-55.

Markus, H., \& Zajonc, R. B. (1985). The cognitive perspective in social psychology. In $G$. Lindzey \& E. Aronson (Eds.), Handbook of social psychology (3rd ed.). New York: Random House.

Morier, D. M., \& Borgida, E. (1984). The conjunction fallacy: A task specific phenomenon. Personality and Social Psychology Bulletin, 10, 243-252. 
Nisbett, R. E., Krantz, D. H., Jepson, C., \& Kunda, Z. (1983). The use of statistical heuristics in everyday inductive reasoning. Psychological Review, 90, 339-363.

Russo, J. E., \& Dosher, B. A. (1983). Strategies for multiattribute binary choice. Journal of Experimental Psychology: Learning, Memory, and Cognition, 9, 676-696.

Tversky, A. (1969). Intransitivity of preference. Psychological Review, 76, 31-48.

Tversky, A., \& Kahneman, D. (1982). Judgments of and by representativeness. In D. Kahneman, P. Slovic, \& A. Tversky (Eds.), Judgment under uncertainty: Heuristics and biases. New York: Cambridge Univ. Press.

Tverksy, A., \& Kahneman, D. (1983). Extensional versus intuitive reasoning: The conjunction fallacy in probability judgment. Psychological Review, 90, 293-315.

Wells, G. L. (1985). The conjunction error and the representativeness heuristic. Social Cognition, 3, 266-279.

Winkler, R. L. (1972). Introduction to Bayesian inference and decision. New York: Holt, Rinehart \& Winston.

Winkler, R. L., \& Murphy, A. H. (1968). "Good" probability assessors. Journal of Applied Meteorology, 7, 751-758.

Wyer, R. S., Jr. (1976). An investigation of the relations among probability estimates. Organizational Behavior and Human Performance, 15, 1-18.

Yates, J. F. (1982). External correspondence: Decompositions of the mean probability score. Organizational Behavior and Human Performance, 30, 132-156.

Yates, J. F., \& Carlson, B. W. (1986). Conjunction errors: Evidence for multiple judgment procedures, including "signed summation." Organizational Behavior and Human Decision Processes, 37, 230-253.

RECEIVED: April 7, 1987 